\title{
Genetic diseases in religious painting
}

\author{
Mircea Gelu Buta
}

MEDICINE AND ART

Babes-Bolyai University, Cluj-Napoca, Romania
DOI: $10.15386 / \mathrm{mpr}-1996$

Manuscript received: 07.12.2020

Received in revised form: 12.01 .2021

Accepted: 27.01.2021

Address for correspondence:

butamircea@yahoo.com

This work is licensed under a Creative Commons Attribution-NonCommercialNoDerivatives 4.0 International License

\begin{abstract}
The attention paid to Trisomy 21, a genetic condition described by Langdon Down in 1866 , is due to concerns about establishing the age of this pathology during evolution. Due to the synergy between medicine and art history, it is possible to reconstruct the diseases that have characterized the most a certain historical period, as well as the perception of the population towards them. Using iconodiagnosis, namely studying works of art through medical imaging, it was found that in Europe, during the Renaissance, Trisomy 21 was represented by Italian and Flemish painters in religiously inspired paintings.
\end{abstract}

Keywords: Trisomy 21, iconodiagnosis, painting

\section{Introduction}

Sculptors and painters have discovered the ideal proportions between the body segments. If the Egyptians have chosen the length of the middle finger as the instrument, the Greek sculptors preferred the length of the straw and Leonardo da Vinci and Michelangelo opted for the height of the head. Beauty is identified with the normal, but the normal implies the idea of variability. Everywhere - in any population - there is a huge individual diversity. They talk about children with disabilities. Their appearance has always been a shock. From ancient times, they shattered a world of hope and threw torrents of unsettling questions.

If at first abnormal children were abandoned to the anxieties of the forests or were thrown dead from the Tayghetos rock, in time they inspired fear and the Egyptian pantheon deified them - the Egyptian goddess Bes was achondroplastic.

Before biology focused on the genesis of malformations, their image entered the art. In a painting by Velázquez, a nobleman from the court of King Philip V of Spain is portrayed as an achondroplastic, and the Duke of Gloucester, the future King Richard III, was described by Shakespeare as having osteoachondroplasia with significant changes in the spine.

The history of medicine always remembers Toulouse Lautrec, who had a pycnodisostosis, which explains the multiple spontaneous fractures [1].

\section{Langdon Down disease - case study}

Trisomy 21 was described by $\mathrm{J}$. Langdon Down in 1866, hence the name Down syndrome used in the medical literature. In 1959, J. Lejeune, M. Gautier and R. Turpin demonstrated that the disease was related to Trisomy of chromosome 21 . The incidence in the general population is 1: 600-700, and in children from mothers over 45 years of age 1:50. Pathogenically it is considered to be a meiotic disjunction favored by the advanced age of the mother. With the help of fluorescent labelling, the cytological proof of the parental origin of the disjunction was made. Mothers of children with Down syndrome have two age curves: a curve with the average age of 34 and a curve with an average age of 28 including cases due to translocations [2].

\section{Elements of clinical diagnosis}

The morphological features associated with Trisomy 21 that underlie the diagnosis are:

- typical facies (epicanthus - skin 
fold that masks the internal angle of the eye, oblique eyelid slits, enlarged nasal pyramid base, open mouth, protruding tongue, square ears)

- short, wide and flat neck with an excess of skin. Abnormalities of the neck region and nasal pyramid are early alterations. They can be diagnosed early by ultrasound

- single palmar skin line (simian line)

- diastasis recti, umbilical hernia

- short and wide hands, clinodactyly of the fifth finger with dysplastic middle phalanx

- the leg with the enlarged interdigital space I-II, there is a planting spike at this level

- the joints are hyperextensible and hyperflexible

- dorso-lumbar kyphosis and hip dislocation

- funnel or convex chest

- syndactyly, polydactyly, congenital crooked leg; radiological - dysplastic pelvis, lateral protrusions of the iliac wings, flattened lower iliac margin, decreased acetabular angle

- muscular hypotonia

- moderate or severe mental retardation

- associated congenital heart disease (DSV, DSA)

The definite diagnosis is confirmed by a karyotype that can highlight:

- Free and homogeneous trisomy 21 (92-95\%) most common maternal meiotic disjunction $(85-90 \%)$

- Trisomy 21 free in mosaic (2-3\%) - mitotic disjunction

- Trisomy 21 by Robertsonian translocation between chromosome 21 and an acrocentric chromosome $(4-5 \%)$

- Partial trisomy $21(1 \%)$ - partial duplication of the long arm of chromosome 21 [3].

Representation of "Trisomy 21" in painting

Since the Renaissance, painters have depicted in their works children with deformed facial features. It should be noted that in a work of art, the distinction between Trisomy 21 and Congenital Hypothyroidism is difficult, because the two conditions have in common, in addition to mental retardation, some dysmorphic features of the face. Here are some examples of famous paintings that have attracted the attention of specialists.

A painting by an anonymous artist on display at the altar of the Aix-la-Chapelle Cathedral in Aachen and dated 1955, entitled „Ecce homo” suggests Trisomy 21. On the rounded face, narrow and oblique eyelid slits, small stuffy nose, open mouth can be distinguished. One can guess that the neck is short and thick. A monkey pretends to comb or ruffle the baby. It can be seen that the hair is curly, while in trisomics it is rather straight, but this aspect could be explained by the fashion of the time. The quality of the clothes makes us think that he came from a wealthy family (Figure 1).
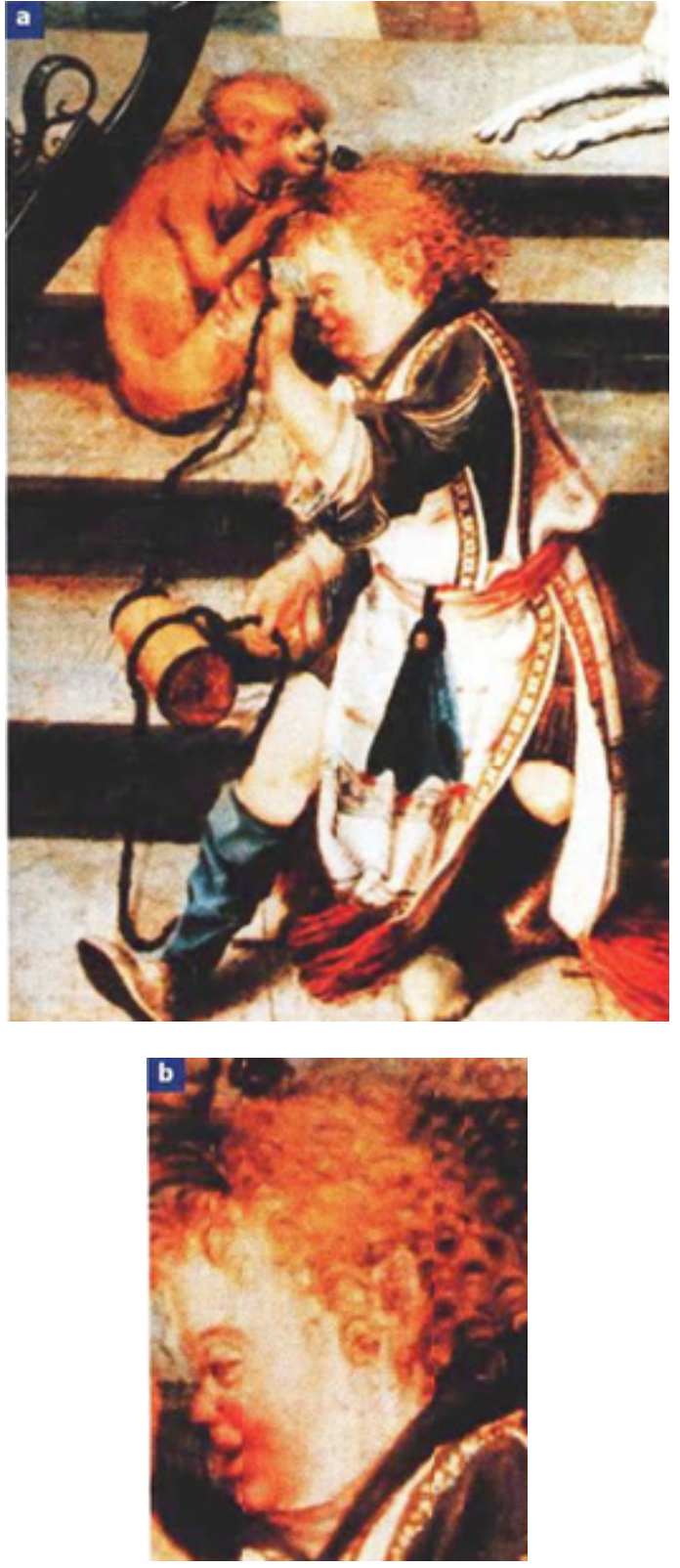

Figure 1. "Ecce homo”, Cathedral of Aix-la-Chapelle, Aachen.

In the work of the painter Jacob Jordaens (15931678) there are two paintings that could suggest children with Down disease. It is about the ,Adoration of the Shepherds" (painted in 1917) and exhibited at the Grenoble Museum. A woman holds a child with oblique eyelid slits, which could suggest a Down syndrome (Figure 2). In another painting, entitled "The Satire and the Peasants", painted between 1635 and 1640, there is a child with oblique eyelid slits and a protruding tongue (Figure 3). Specialists claim that one of the painter's children probably served as a model. A little girl, Elisabeth, had been born into his family, with a precarious state of health that could have been due to a Trisomy 21 . 


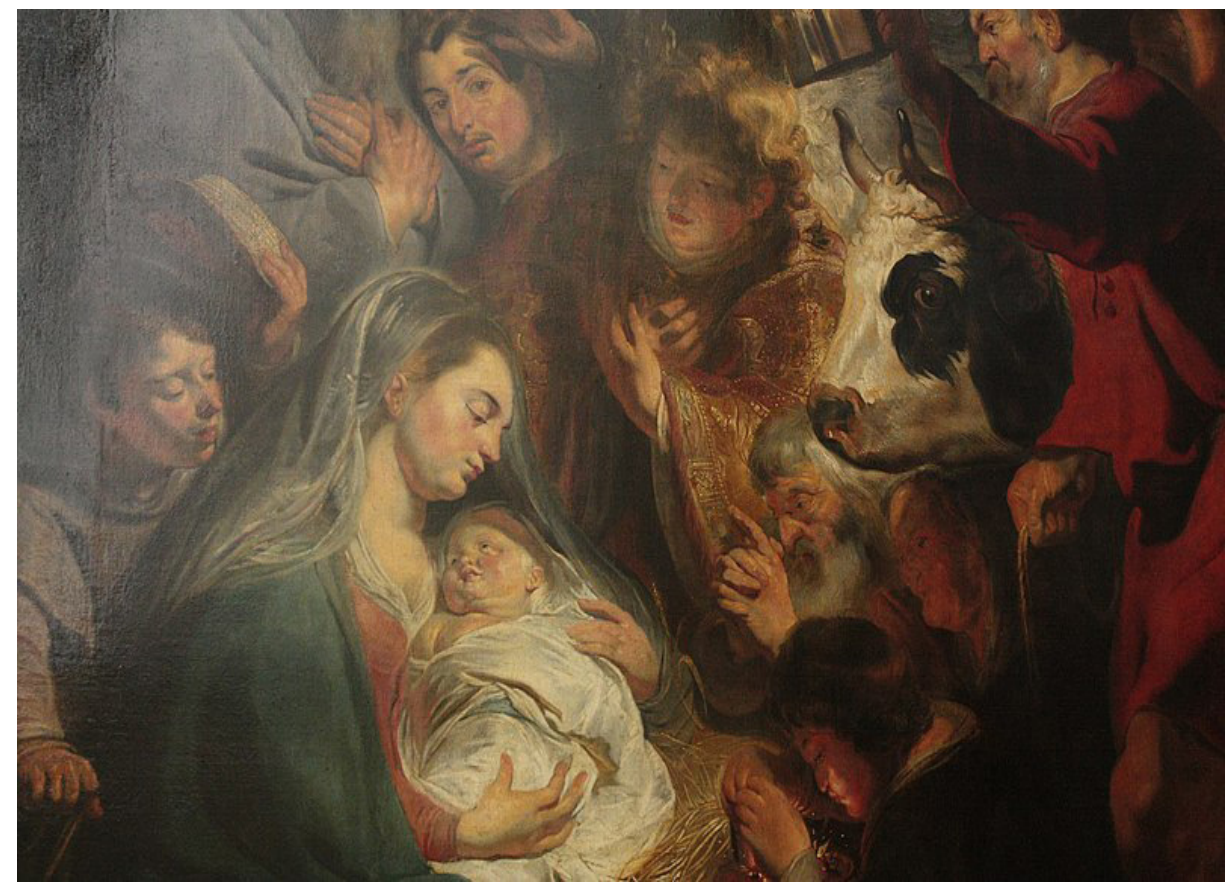

Figure 2. "The Adoration of the Shepherds" - 1917, Jacob Jordaens, Grenoble Museum.



Figure 3. "Satire in the house of the peasants" (1635-1640), Jacob Jordaens. 
Quite convincing is the painting painted by Andrea Mantegna in 1460, entitled „Madonna and Child”. The features of the baby Jesus are suggestive: oblique eyelid slits, small nose, open mouth (Figure 4).

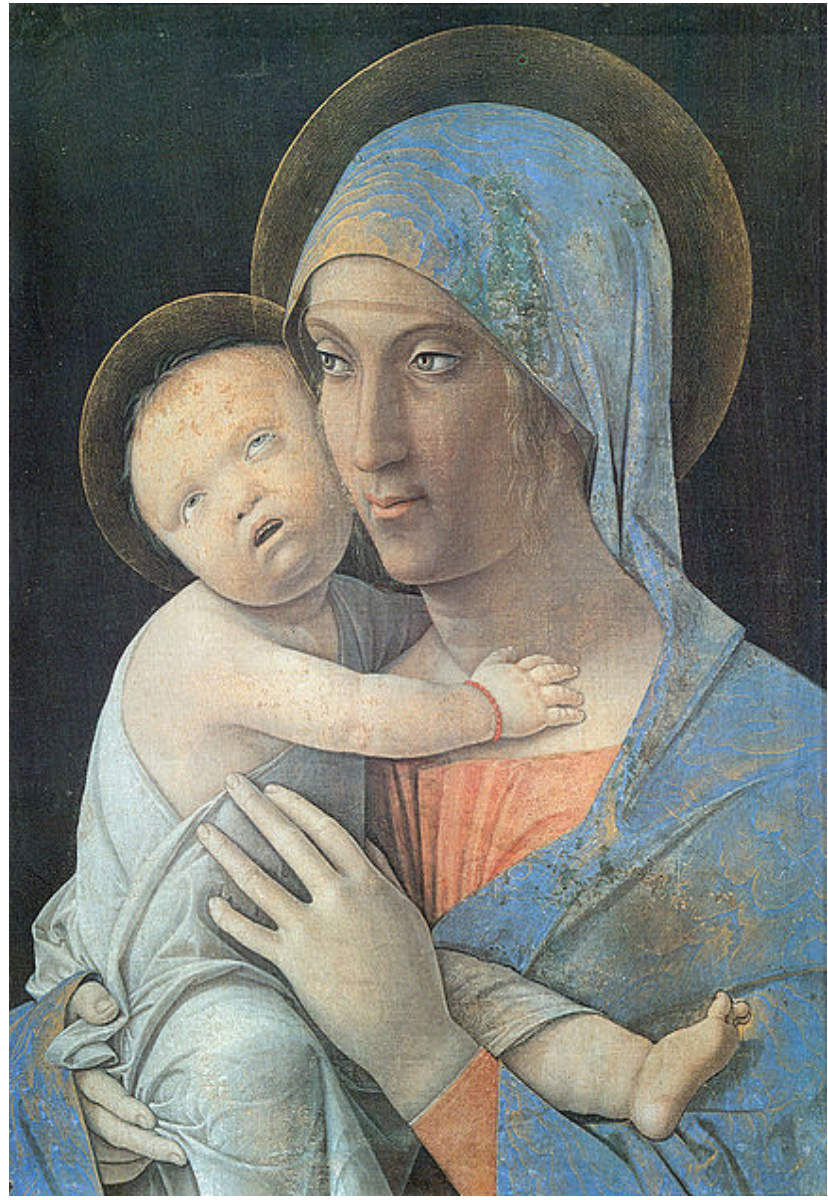

Figure 4. "Madonna and Child" (1480 - 1495) Andrea Mantegna, Carra Academy Collection.

Another painting, attributed to Mantegna, entitled „Madonna and Child with Saint Jerome and Saint Louis of Toulouse" shows a child who could be trisomic: hypertelorism, oblique eyelid slits, open mouth with protruding tongue, square hands with the little finger curved. His facial expression evokes mental retardation. The diagnosis with hypothyroidism is difficult to make (Figure 5).

A third painting attributed to Mantegna, ,Virgin and Child" found at the Boston Museum of Fine Arts, is the subject of controversy: for doctors who have studied this picture, the child's features may correspond to Trisomy 21: oblique eyelid slits, epicanthus, flattened nasal root, protrusion of the tongue, clinodactyly of the fifth toe, the wide space between the first and second toe, are elements that support this diagnosis. Instead, the museum's experts claim that the painting was not painted by Mantegna, but by a student or an imitator and only the lack of his talent would be responsible for a coincidence with the symptoms of Down's disease. It should be noted that the Virgin's neck suggests the presence of goiter, which induces the idea of hypothyroidism in the child (Figure 6) [4].
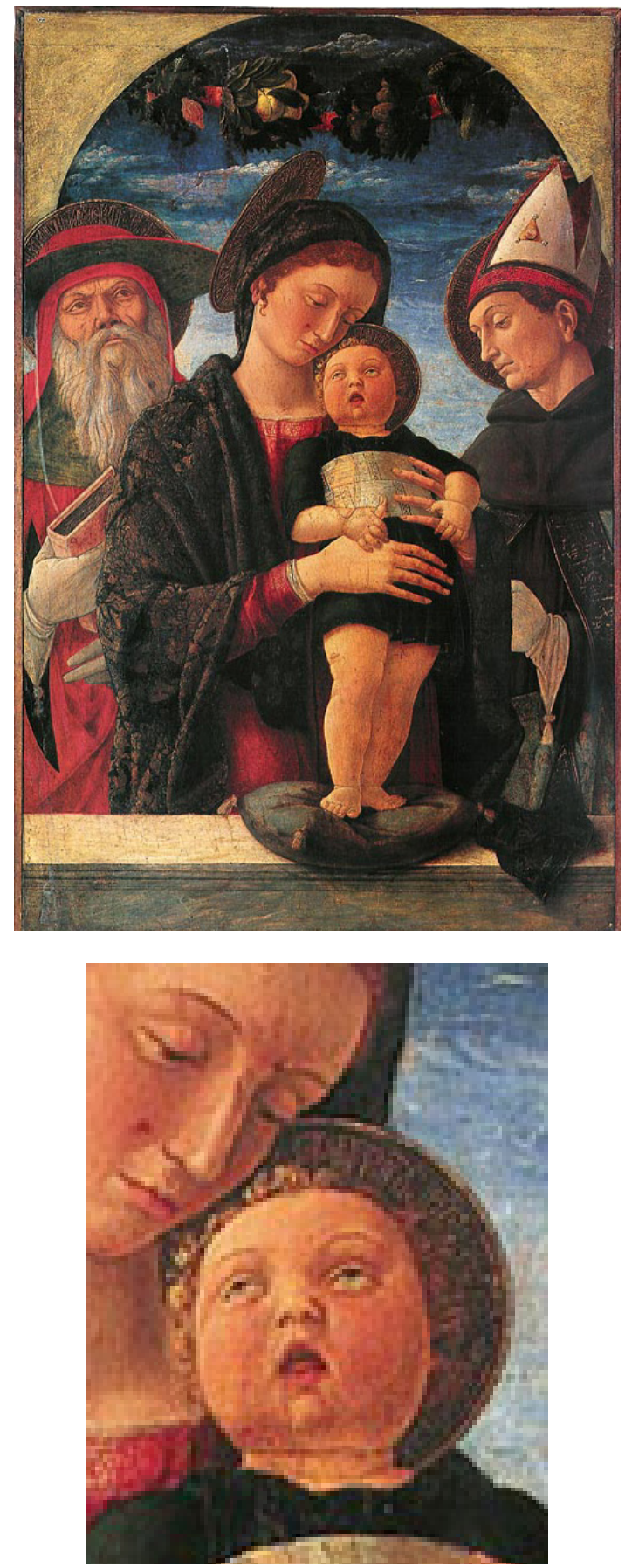

Figure 5. "The Virgin and Child with Saint Jerome and Louis of Toulouse" 1455, Andrea Mantegna, Jacquemart-André Museum Collection, Paris. 


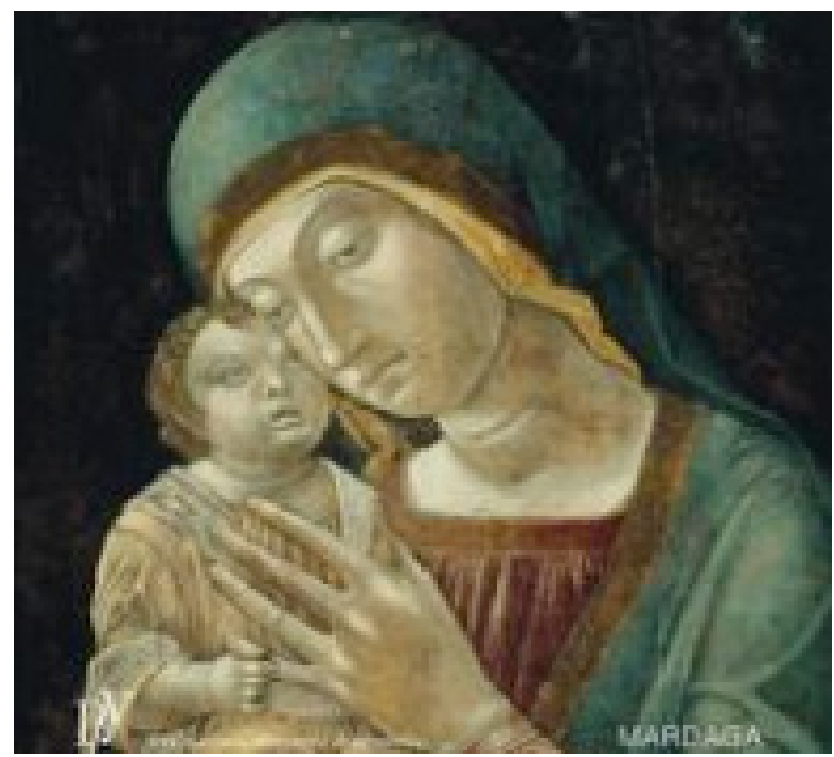

Figure 6. "The Virgin and Child", Boston Museum of Fine Arts.

It has been suggested that Mantegna's wife, Nicolosia, Jacopo Bellini's daughter, served as a model for Virgo. She is known to have had many children, many of whom died at an early age. Of the four survivors, one appears to have been affected by Trisomy 21 . According to another hypothesis, the painter painted a portrait of a child of the Louis III Gonzague family, Marquis of Mantua [5].

In a small painting by Mantegna, entitled „Madonna and Child", exhibited at the Ufizzi Gallery, the child's face has dysmorphic stigmas suggestive of Trisomy 21 (Figure 7) [4].

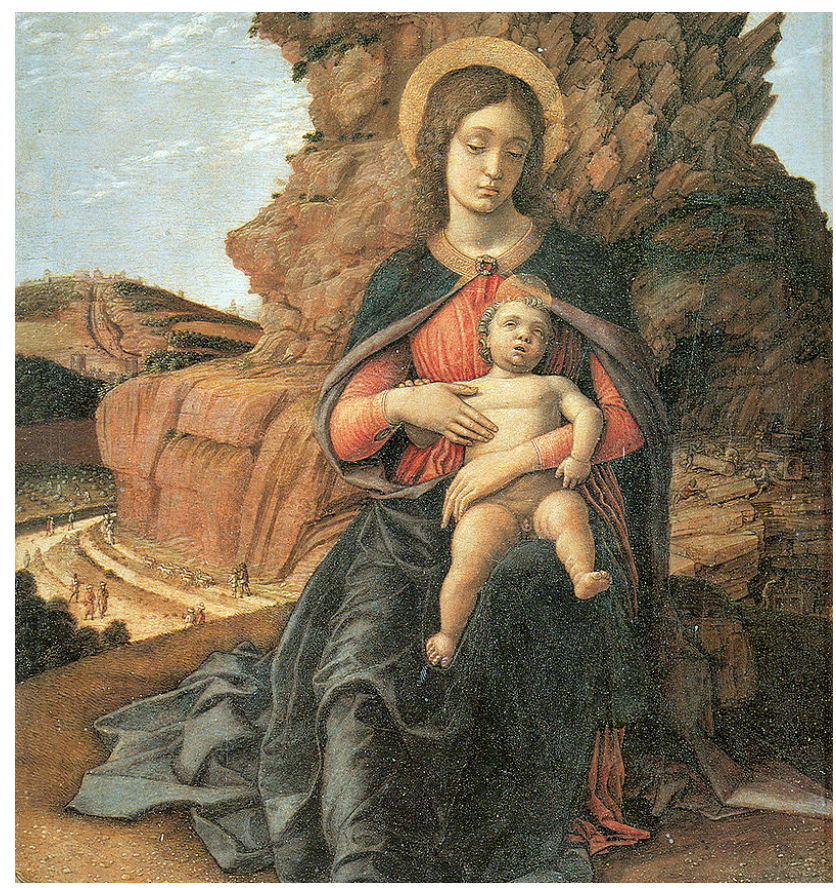

Figure 7. "The Virgin and Child" 1489, Andrea Mantegna, Uffizi Gallery, Florence.
There is a painting by Filippo Lippi (1406-1469), called „Madonna of Humility”, painted in 1430, in which the Virgin is surrounded by a group of angels with children's faces (Figure 8). Those at the top have dysmorphia of the face evocative of mental retardation. The head from the left of the Virgin could be affected by Trisomy 21 (Figure 9). Commenting on the painting, Brian Stratford claims that these children were painted from memory. For him, Filippo Lippi would have remembered the childhood he spent in an orphanage [4].

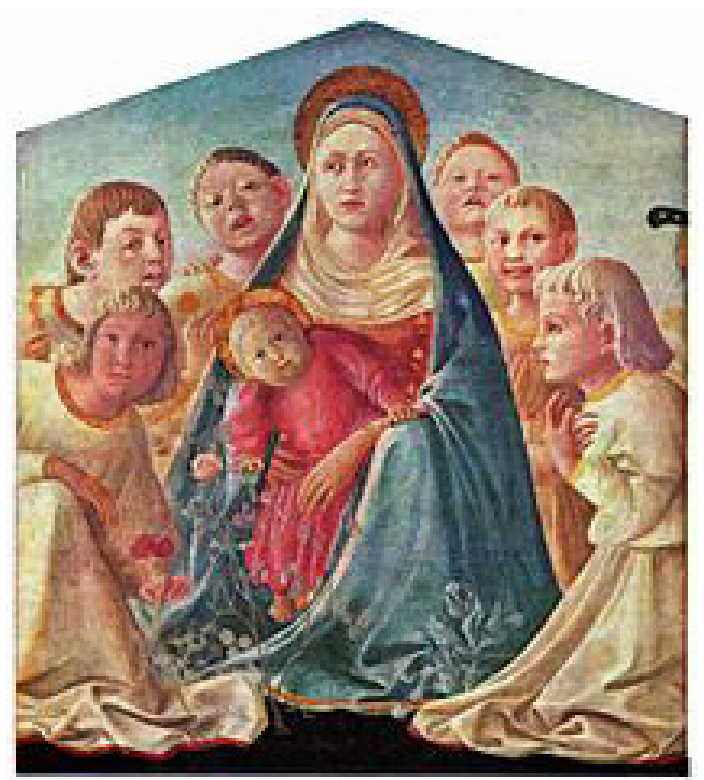

Figure 8. "The Humble Virgin" 1430, Filippo Lippi, Castle, Milano.

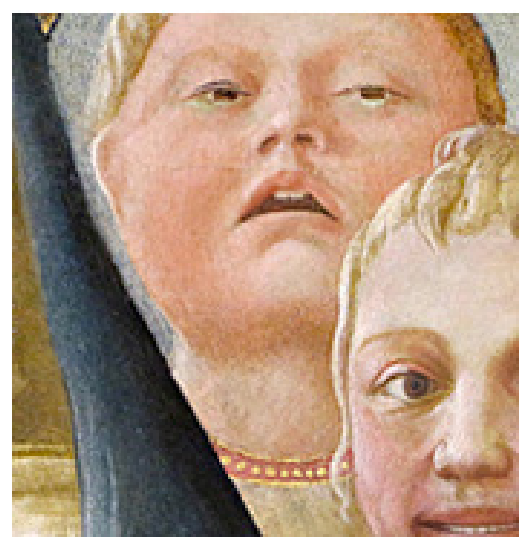

Figure 9. "The Humble Virgin" 1430, Filippo Lippi - detail.

In a painting by an anonymous Flemish artist entitled „The Adoration of the Christ child” on display at the Metropolitan Museum of Art New York, the face of a child with Trisomy 21 stigmas appears: round face, flattened nasal root, oblique eyelid slits with epicant, small mouth. The face of a shepherd near the child also has 
Trisomy 21 characters (Figure 10). Many wonder why it was necessary to choose a child with Down's Disease to represent an angel. Probably if the disease had been known, this would not have happened to the extent that it would have contradicted Martin Luther's view that people with disabilities were possessed by demons [6].
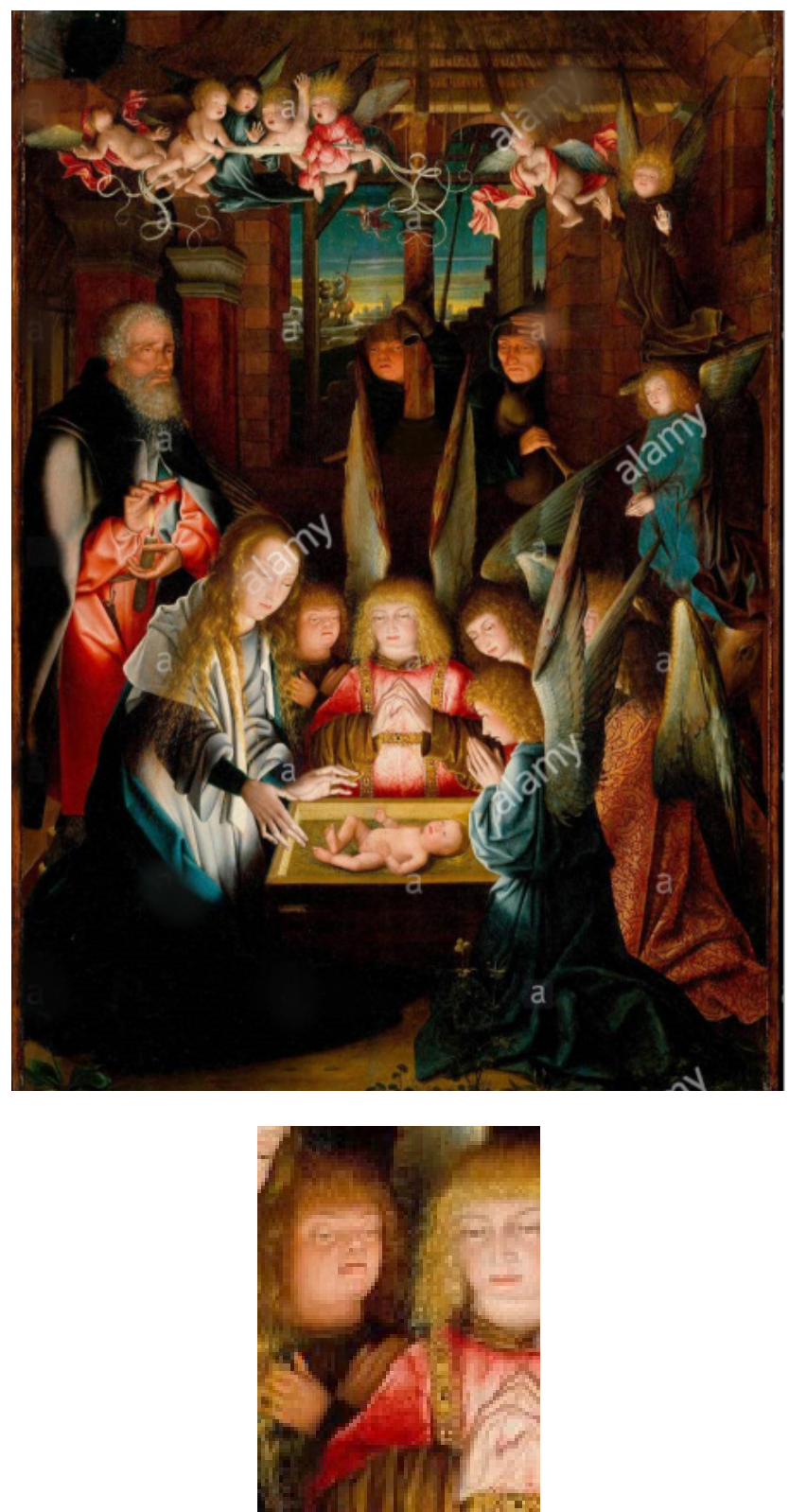

Figure 10. "Adoration of the Christ Child", Flemish painter anonymous, New York Metropolitan Museum of Art.

\section{Comments and discussion}

Albert Einstein once said, "The most beautiful experience we can have is that of mystery." Indeed, the mystery has gone with us throughout the biological history of mankind, its extent overwhelms us. It took a huge effort of imagination to understand that behind it lies the unknown and that the purpose of science is to reveal it. We try to lean with endless curiosity on the past to reconstruct everything that can be rebuilt, even with a high coefficient of improbability, to understand what we are and to sketch a predictable future.

In the medical literature, the moment of the appearance of the pathology related to chromosome 21 is the subject of a debate. Noting that the clinical features of this condition do not appear to have been individualized before the middle of the $19^{\text {th }}$ century, several authors wondered if this was not a recent pathology. Naturally, researchers are trying to find explanations. The first assumption would be the short survival of those affected due to susceptibility to infections and/or associated malformations. The second explanation is related to the lifespan of mothers. Over the centuries, only half of the female population was over the age of 35 , so a limited number of affected children were born. Ultimately, whatever the cause, it is certain that the clinical picture of the disease did not attract the attention of doctors until the $19^{\text {th }}$ century. In this situation, the visual arts can be of great help to the history of medicine in the study of the antiquity of Trisomy 21.

The concept of „Iconodiagnosis” was introduced in 1983 by Anneliese Pontius, a psychiatrist at Harvard University, with the intention of demonstrating the ancient presence of Crouzon syndrome in the Cook Islands [7]. It was later developed by M. Grmeck and D. Gourevitch, for whom the retrospective diagnosis ,is based on a morphological truth seen by the artist without being conditioned, transformed or normalized by a formal medical science" [6].

As in Byzantine art, painters render a spiritual reality, they use models symbolically, for which the body parts do not have normal anatomical dimensions. The eyes are usually large, almond-shaped and vivid. The nose is painted long and thin, and the mouth small. The fingers are long and Adam's apple is voluminous. Unlike Hellenistic and Renaissance art, where the beauty of the human body prevails in its naturalistic appearance, in the Orthodox icon the body often disappears under clothing resembling a Roman toga. The body is covered, hidden, the mystery of its transfiguration is guessed by the solar folds of the garments. The natural anatomy particularly deformed, as well as the apparent rigidity, only emphasize the inner power that animates them. The garments no longer cover bodies, but souls, taking on their diaphanous "colors". The folds of the garments no longer express the physical movements, but the spiritual rhythm of the whole being. So far, we have not been able to identify in the Byzantine icons, faces with stigmas of genetic diseases. That is why I have studied religious paintings exhibited in Western European museums in Catholic and Protestant countries. 
In our analysis, the diagnosis of Trisomy 21 was suggested by the facial stigmas, the peculiarities of the hands and feet characteristic for the disease. Supporting the diagnosis only on clinical elements can sometimes lead to erroneous conclusions. For example: if initially in the painting ,Lady Cockburn and her children” by the painter Joshua Reynolds (1723-1792), it was thought that one of the children would be affected by Trisomy 21 , the assumption was refuted by the subsequent evolution of the character. It is about Admiral George Cockburn, the person who commanded the ship that took Napoleon to St. Helena Island (Figures 11,12) [8].
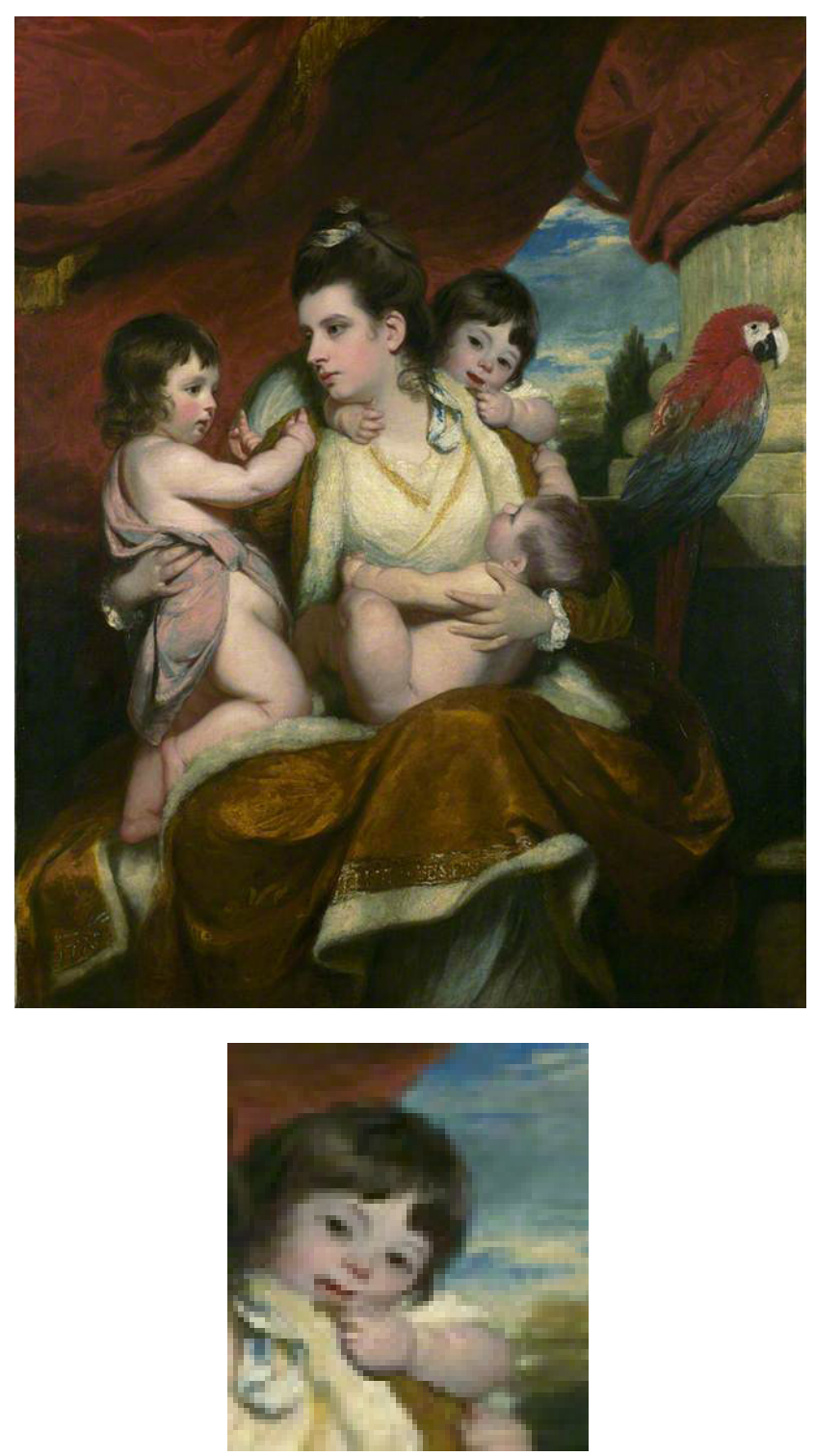

Figure 11. "Lady Cockburnand and her children", Joshua Reynolds (1723-1792), National Gallery, United Kingdom.
Also, the differential diagnosis with hypothyroidism should be considered, which in the images can be easily confused with Trisomy 21.

As the diagnosis of Trisomy 21 can only be supported by performing a karyotype, doubt always remains allowed, even in the presence of a complete clinical picture. To avoid endless controversy, the use methods of quantitative analysis has been proposed, in particular geometric morphometry techniques, to verify whether the features of a painting or figurine correspond to those of a subject identified as Trisomy 21 on medical data.

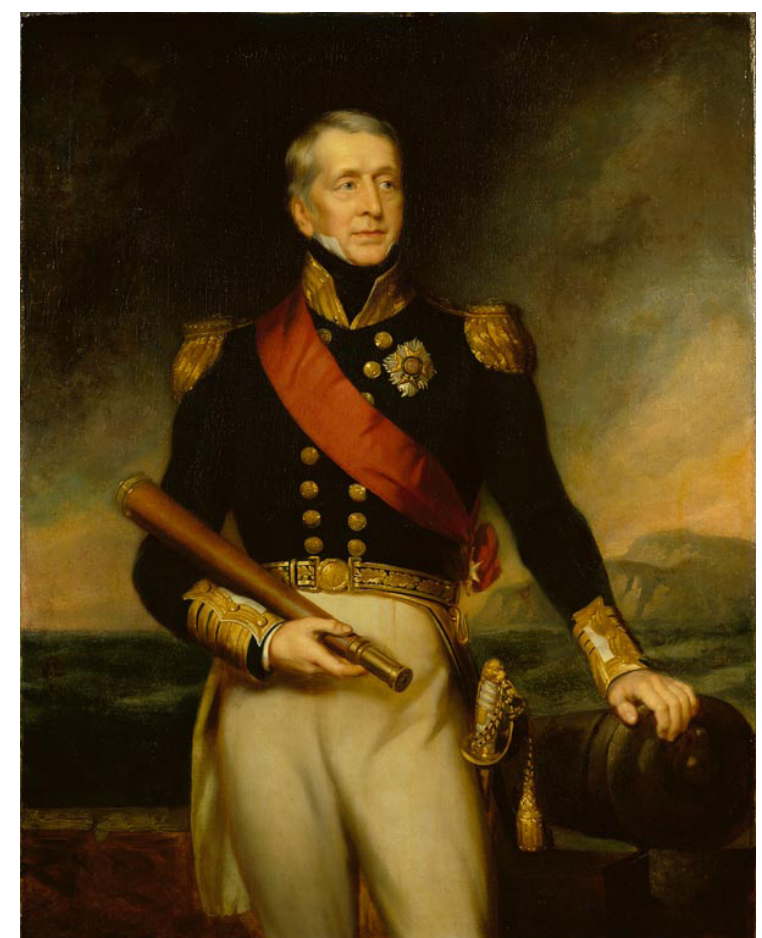

Figure 12. "Portrait of Admiral George Cockburn" 1874, John Lucas.

\section{Conclusions}

1. Due to the synergy between medicine and art history, it is possible to reconstruct the diseases that have characterized the most a certain historical period, as well as the perception of the population towards it.

2. In Europe, during the Renaissance, Trisomy 21 is represented by Italian and Flemish painters in religiously inspired paintings.

3. The disease is due to a chromosomal mutation, and its age is uncertain. 


\section{References}

1. Maximilian C. Drumurile sperantei [The ways of Hope]. Albatros: Bucharest; 1989, pp. 190 [Romanian]

2. Geormăneanu M. Patologie indusa prenatal [Prenatal induced pathology]. Ed. Medicală; 1978: pp. 307-308 [Romanian]

3. Stratford B. Down's syndrome: Past, Present and Future. London: Penguin Books; 1989.

4. Stratford B. Down's syndrome at the court of Mantua. Matern Child Health 1982; 7: p. 150-154.

5. Merke F. Geschichte und Ikonographie des endemischen
Kropfes und Kretinismus [History and iconography of endemic goitre and cretinism]. Bern, Stuttgart, Wien: Verlag Hans Huber; 1971 [German]

6. Stahl A. Tourane P. La trisomie 21 dans les arts visuels [Trisomy 21 in visual arts]. Archives de Pédiatrie 2013; 20:1342-1351 [French]

7. Grmek M, Gourevitch D. Les maladies dans l'art antique [Diseases in ancient art]. Paris: Fayrd; 1998 [French]

8. Tumpeer IH.The ease of erring in the diagnosis of mongolism from premedical portraits. Soc soc Hist Med Bull. 1939;5:88104. 